\section{OXIDATION IN THE MANUFACTURE OF TNT ${ }^{1}$}

\author{
By ALBERT S. EASTMAN
}

The nitration of cotton and the nitration of glycerin are carried out at such low temperatures that they are oxidized only very slightly by the mixture of nitric and sulfuric acids, and the spent acids contain only about I per cent of $\mathrm{HNOSO}_{4}$, as determined by titration with potassium permanganate. This substance represents the reduction products of the nitric acid, and is assumed to be formed by the union of nitrous acid or lower oxides of nitrogen with sulfuric acid in the absence of much water.

The nitration of toluene, however, is carried out at such a high temperature that there is considerable oxidation of the nitrotoluenes with a corresponding decrease in yield of TNT. The spent acid contains about I 8 per cent of $\mathrm{HNOSO}_{4}$ and an equivalent amount of oxygen must either have gone to oxidize some substance, or else it must have escaped in the free state. The nitrator contains a mixture of the various isomeric di- and trinitrotoluenes. In attempting to identify the products of the oxidation of these nitrotoluenes, we isolated 2,4-dinitrobenzoic acid. This is found in part of the charges, but most of them do not contain it in appreciable amounts. The total amount of organic acids formed by oxidation of the methyl group of the toluene has been determined in the spent acid the following way:

The nitric acid was removed from the spent acid by evaporation, and the sulfuric acid was removed by adding enough barium hydroxide to neutralize the solution, and filtering off the barium sulfate. The filtrate then contained the soluble barium salts of the organic acids, carboxylic acids formed by oxidation of the methyl group of the toluene, and sulfonic acids formed by the action of the strong sulfuric acid in the nitration.

The barium salts of the organic acids thus obtained were then analyzed by evaporating an aliquot part of the above filtrate to dryness, and weighing the dry barium salts. Then the residue was ignited in air to convert the barium salts of the carboxylic acids to barium carbonate and the barium salts of the sulfonic acids to barium sulfate. After weighing the mixture of carbonate and sulfate, the carbonate was removed by extraction with hydrochloric acid and the sulfate weighed. This furnished data from which the loss of toluene due to sulfonation and the loss due to oxidation to carboxylic acids, could be calculated. Assuming one acid group per molecule of toluene, there was 0.39 per cent loss of toluene by sulfonation and I. 24 per cent loss of toluene by oxidation to organic acid; total loss; 1.63 per cent.

The ignition loss from the dry barium organic salts may be regarded as representing the total loss of toluene, and this loss amounted to I.86 per cent of the toluene used for nitration, which is an approximate check.

This loss of 1.24 per cent is so small as to account

1 Read before the Division of Industial Chemists and Chemical Fingineers, 57th Meeting of the American Chemical Society, Buffalo, April 7 to 11,1919 . for the formation of only a small part of the 18 per cent $\mathrm{HNOSO}_{4}$ present in the spent acid, and it was therefore necessary to look for other oxidation products. The next experiments were designed to show whether any gases are formed during nitration. For this purpose the nitration was carried out in glass in an atmosphere of carbon dioxide, and the gas evolved was collected over sodium hydroxide solution, which absorbed the carbon dioxide. Separate nitrations were run in air to determine the amount of carbon dioxide liberated, the dioxide being absorbed in concentrated sodium hydroxide solution. In these experiments, dinitrotoluene or bi-oil, as it is called, was nitrated to trinitrotoluene. This is the third stage in the nitration of toluene to TNT.

It was found that carbon dioxide, carbon monoxide, nitrogen, and oxygen are evolved during nitration. One hundred parts of bi-oil, containing about ${ }_{5} 5$ per cent TNT, liberate 7.39 parts carbon dioxide by weight, 0.495 part carbon monoxide, 0.409 part nitrogen, and 0.016 part free oxygen. The carbon dioxide and the carbon monoxide together represent the loss of sufficient TNT to lower the yield by about 5 per cent. As the yield obtained in the manufacture of TNT is about 86 per cent on the average, this loss amounts to more than one-third of the total loss sustained in the whole process of manufacturing TNT.

The composition of the gas liberated may vary considerably, even during a single nitration, as is shown by the varying inflammability of the mixture. The proportion of carbon monoxide may be so high under certain conditions that the gas mixture becomes explosive, and this may account for various explosions which have occurred in TNT nitrators, where the top of the nitrator has been blown off, without exploding the charge of TNT.

The experimental work described in this paper was carried out,by Dr. W. J. Keith and Dr. J. E. Schott.

HERCULES POWDER COMPANY K TENVII, NEW JERSEX

\section{STUDIES ON THE NITROTOLUENES. III-BINARY SYSTEMS OF THE COMPONENTS $p$-NITRO- TOLUENE, I,2,4-DINITROTOLUENE, $I, 2,4,6$-TRINITROTOLUENE ${ }^{1}$}

By JAMES M. BELI. AND ChaRLES H. Herty, JR. Received July 7,1919

In the nitration of toluene by various methods, some of which are described by Hoff man, ${ }^{2}$ the product is always composed of several nitrotoluenes. The chief compounds are: $p$-Nitrotoluene (MNT), onitrotoluene, $I, 2,4$-dinitrotoluene (DNT), and $\mathrm{I}, 2,4,6-$ trinitrotoluene (TNT). Present also, but in smaller quantity, are $m$-nitrotoluene and I,2,6-dinitrotoluene. For an investigation of the conditions which would give maximum yields of any desired nitrotoluene, it is necessary first to have an accurate method of analysis of the product. Analyses by direct

1 This paper is the third of a series dealing with the freezing points and thermal properties of the nitrotoluenes, the investigation having been undertaken at the request of the Division of Chemistry and Chemical Technology of the National Research Council.

2 Bureau of Mines, Technical Paper 146 (1916). 